OPEN ACCESS

Edited by:

Thierry MLB Vander Borght,

Catholic University of

Louvain, Belgium

Reviewed by:

Sebahat Ocak

CHU UCL Namur Site Godinne

Namur, Belgium

Virginia Liberini,

University of Turin, Italy

Angelo Castello,

IRCCS Ca 'Granda Foundation

Maggiore Policlinico Hospital, Italy

*Correspondence:

Karim Amrane

kamrane@ch-morlaix.fr

†These authors have contributed equally to this work

Specialty section

This article was submitted to

Nuclear Medicine,

a section of the journal

Frontiers in Medicine

Received: 05 April 2021

Accepted: 20 July 2021

Published: 30 September 2021

Citation:

Amrane K, Campedel L, Le Meur C, Abgral R, Kharroubi D and Cadranel $J$ (2021) Case Report: Two Rare Cases of Complete Metabolic Response to Crizotinib in Patients With Rearranged ROS1 and ALK Metastatic Non-small Lung Cancer. Front. Med. 8:691253.

doi: 10.3389/fmed.2021.691253

\section{Case Report: Two Rare Cases of Complete Metabolic Response to Crizotinib in Patients With Rearranged ROS1 and ALK Metastatic Non-small Lung Cancer}

\author{
Karim Amrane ${ }^{1,2 \star t}$, Luca Campedel ${ }^{1 \dagger}$, Coline Le Meur ${ }^{2 \dagger}$, Ronan Abgral ${ }^{3}$, Dris Kharroubi ${ }^{4}$ \\ and Jacques Cadranel ${ }^{5}$ \\ ${ }^{1}$ Department of Oncology, Pitié Salpêtrière Hospital, Paris, France, ${ }^{2}$ Department of Oncology, Centre Hospitalier des Pays de \\ Morlaix, Morlaix, France, ${ }^{3}$ Department of Nuclear Medicine, University Hospital of Brest, Brest, France, ${ }^{4}$ Department of \\ Nuclear Medicine, Pitié Salpêtrière Hospital, Paris, France, ${ }^{5}$ Department of Pneumology and Thoracic Oncology, Tenon \\ Hospital, AP-HP and Sorbonne Université, Paris, France
}

Crizotinib is a tyrosine kinase inhibitor (TKI) indicated in first-line treatment of rearranged c-ros oncogene 1 (ROS1) and anaplastic lymphoma kinase (ALK) metastatic non-small-cell lung cancer (NSCLC). However, the common response reported after treatment is partial and few complete responses have been reported in PROFILE studies with computed tomography (CT) evaluation. To date, only one case report of complete metabolic response on 2-deoxy-2-[ $\left[{ }^{18} \mathrm{~F}\right]$ fluoro-D-glucose positron emission tomography-computed tomography $\left({ }^{18} \mathrm{~F}-\mathrm{FDG}-\mathrm{PET} / \mathrm{CT}\right)$ was published, reporting on a patient with ROS1 rearranged NSCLC. We highlighted the ${ }^{18}$ F-FDG-PET/CT useful approach for therapeutic assessment of TKI in metastatic mutated NSCLC reporting two complete metabolic responses in patients treated with crizotinib for a rearranged ROS1 and a metastatic ALK NSCLC.

Keywords: ROS1, ALK, therapeutic assessment, FDG-PET/CT, crizotinib, NSCLC

2-deoxy-2-[ $\left.{ }^{18} \mathrm{~F}\right]$ fluoro-D-glucose positron emission tomography-computed tomography $\left({ }^{18} \mathrm{~F}-\mathrm{FDG}-\mathrm{PET} / \mathrm{CT}\right)$ allows for the staging of non-small cell lung cancer (NSCLC) with a sensitivity of $93 \%$ and a specificity of $96 \%$ (1). Furthermore, metabolic imaging may be of interest for tyrosine kinase inhibitors (TKI) in metastatic NSCLC with oncogenic drivers $(2,3)$.

Rearrangement of the anaplastic lymphoma kinase (ALK) gene and the c-ros oncogene 1 (ROS1) are present respectively in 5\% (4) and 2\% (5) of NSCLC. These specific molecular abnormalities are characteristic of adenocarcinoma histology in young patients with a history of light or no smoking $(4,6)$.

The rearrangement of ALK is a small inversion within chromosome $2 \mathrm{p}$ that results in the formation of a fusion gene, comprising portions of the echinoderm microtubule-associated protein 4 (EML4) gene and the ALK gene; this results in a cytoplasmic protein with constitutive kinase activity $(7,8)$. ROS1 is located on chromosome $6 \mathrm{q} 22$ and the fusion is the result of a combination of the $3^{\prime}-5^{\prime}$ regions of ROS1; this produces a constitutively active fusion kinase protein $(9,10)$. The detection of ALK and ROS1 rearrangements includes fluorescence in situ hybridization (FISH), immunohistochemistry (IHC), or reverse transcription polymerase chain reaction (RT-PCR) (11). 

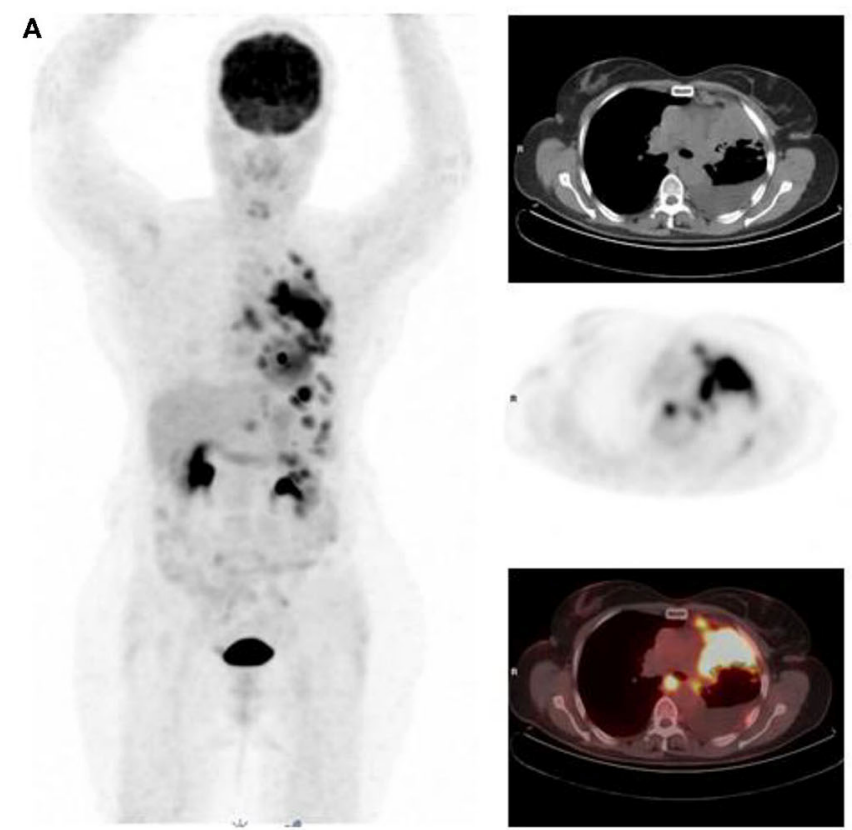

B
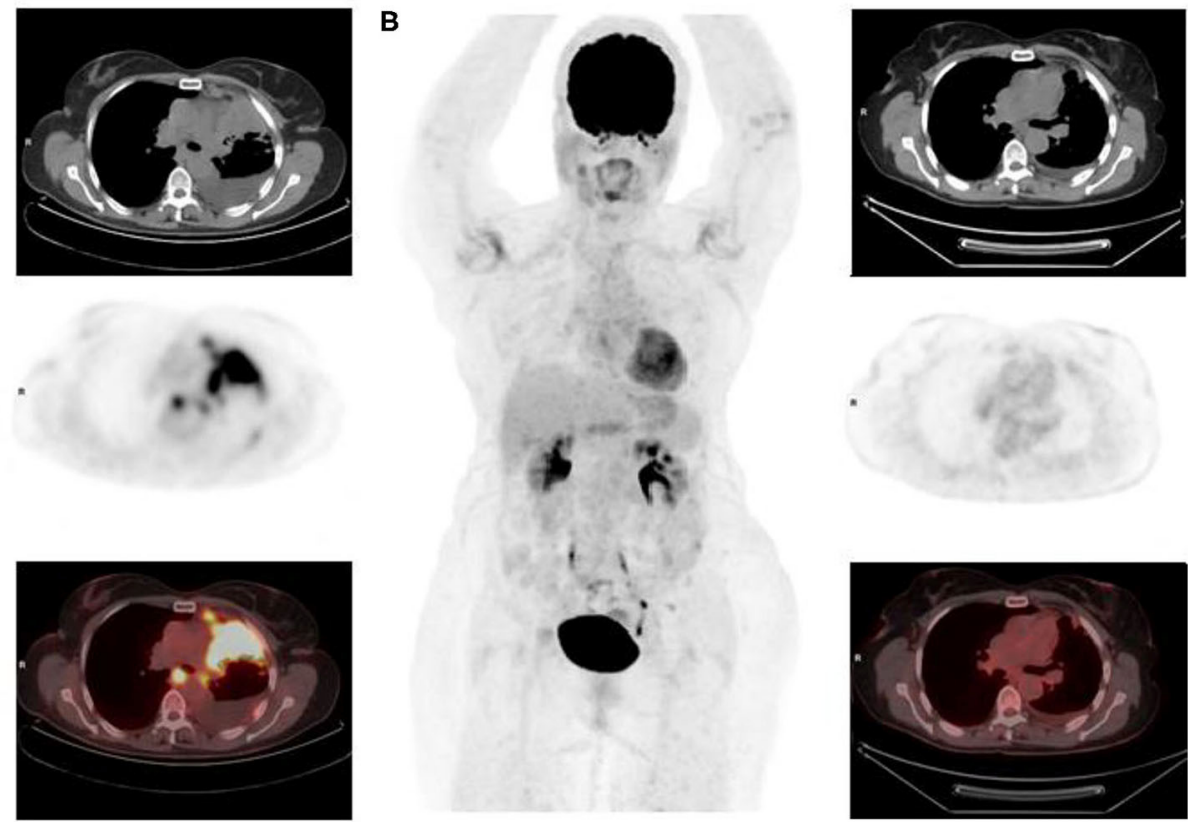

C

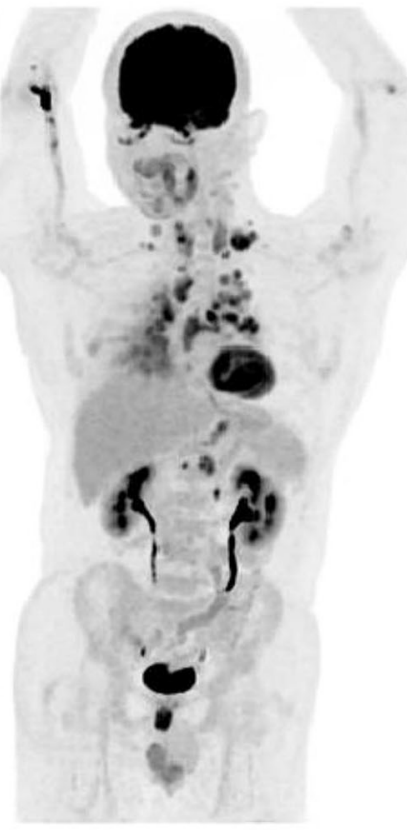

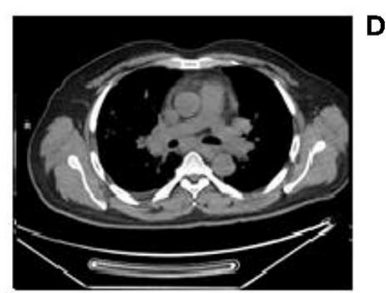
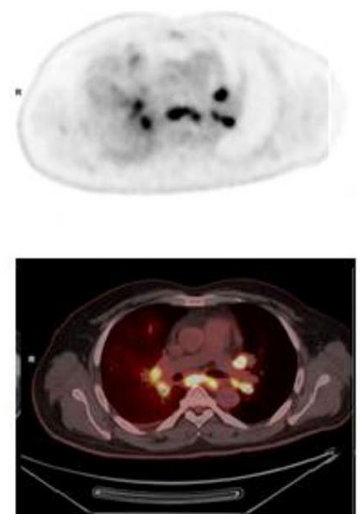

D
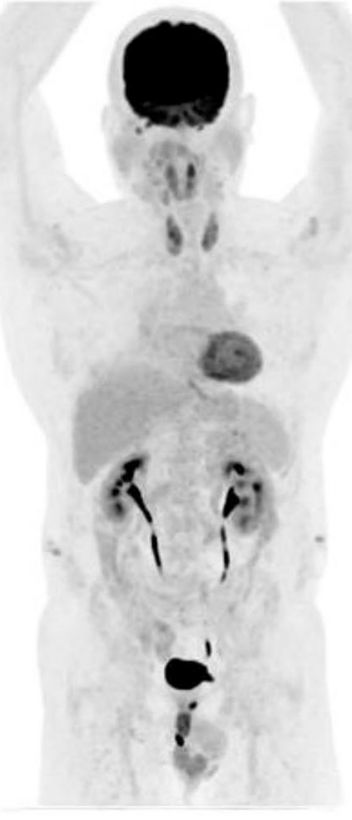
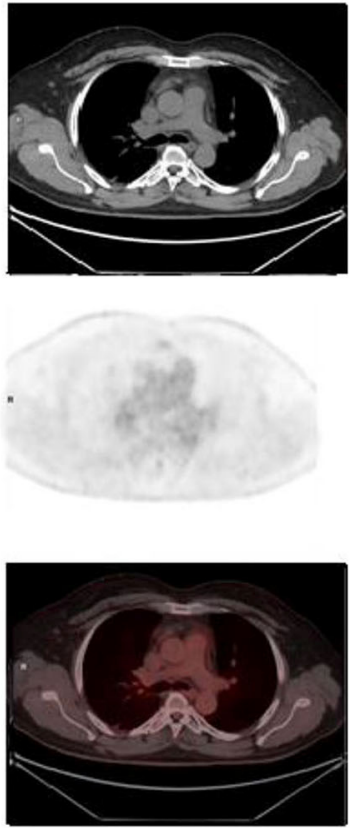

FIGURE 1 | First, we report a non-smoker, 81-year-old African woman, diagnosed with ALK-rearranged lung adenocarcinoma on progressive dyspnea and fatigue with performance status (PS) $=2$. A baseline ${ }^{18} \mathrm{~F}$-FDG-PET/CT was performed, confirming a metabolic metastatic disease (left pleural nodes with pleurisy associated with upper and lower diaphragmatic lymph nodes) (A) maximum intensity projection image, chest CT, ${ }^{18}$ F-FDG-PET, and fused ${ }^{18}$ F-FDG-PET /CT. After 3 months of crizotinib, clinical improvement of the patient was observed (PS $=1$ and disappearance of dyspnea) supported by a CMR on ${ }^{18} \mathrm{~F}$-FDG-PET as well as a CR on CT. This response was maintained for at least 28 months (B). The other patient is a non-smoker, 58-year-old Asian man with a previous medical history of controlled arterial hypertension and pruritus ani, diagnosed with ROS1 rearrangement NSCLC adenocarcinoma. Staging ${ }^{18}$ F-FDG-PET/CT showed multiple hypermetabolic lymph nodes and lymphangitic carcinomatosis (C). After 3 months of crizotinib, ${ }^{18}$ F-FDG-PET and CT showed respectively CMR and CR (D) that was still maintained 10 months later which corroborate the improvement of patient's performance status (2 to 0 ). 
ROS1 and ALK receptors have homology, and some ALK TKI have inhibitory activity against ROS1 (10). Crizotinib is the first oral ATP competitive selective inhibitor of both ALK and ROS1 tyrosine kinases (TK) that inhibits tyrosine phosphorylation (12). A randomized trial PROFILE $1014(13,14)$ and phase 1 trial PROFILE 1001 (15, 16), which assessed patients respectively with NSCLC ALK and ROS1 rearrangement, have shown that crizotinib increases the survival rate of patients in first-line treatment compared to standard of care (SoC). In fact, the median overall survival (OS) was not reached (NR) with crizotinib (95\% CI, 45.8 months to NR) and 47.5 months with chemotherapy (95\% CI, 32.2 months to NR) in the PROFILE 1014 trial and median OS was 51.4 months (95\% CI, 29.3 to NR) in the PROFILE 1001 trial. Furthermore, according to the evaluation of computed tomography (CT), few complete responses (CR) were reported in patients receiving crizotinib (only three of 172 with ALK and six of 53 with ROS1 rearrangement).

In metastatic NSCLC, CT is the standard for assessing the response to treatment. However, based on the results of an exploratory study by Kerner et al. (17), ${ }^{18}$ F-FDG-PET/CT assessment of tumor responses was more easily undertaken compared to $\mathrm{CT}$ with earlier progression detection. Contrary to the CT field of view, it also offers the possibility of detecting progression in the whole body.

To date, only two case reports of ${ }^{18}$ F-FDG-PET/CT complete metabolic responses (CMR) have been published concerning patients with NSCLC ROS1-rearrangement treated with crizotinib $(18,19)$ and none for NSCLC ALK-rearrangement. This paper reports on two cases of CMR with crizotinib on ${ }^{18}$ F-FDG-PET/CT assessment (Figure 1).

The CMR explanation could be that crizotinib suppressed cell viability and ALK / ROS1 phosphorylation, as well as the phosphorylation of the downstream survival effectors Erk1/2 and Akt. E, which induces apoptosis in tumor tissue $(8,20)$.

\section{REFERENCES}

1. Salaün P-Y, Abgral R, Malard O, Querellou-Lefranc S, Quere G, Wartski $\mathrm{M}$, et al. Good clinical practice recommendations for the use of PET/CT in oncology. Eur J Nucl Med Mol Imaging. (2020) 47:2850. doi: 10.1007/s00259-019-04553-8

2. Koizumi T, Fukushima T, Gomi D, Kobayashi T, Sekiguchi N, Mamiya $\mathrm{K}$, et al. Correlation of early PET findings with tumor response to molecular targeted agents in patients with advanced driver-mutated non-small cell lung cancer. Med Oncol Northwood Lond Engl. (2017) 34:169. doi: 10.1007/s12032-017-1032-0

3. Shao D, Cheng Y, Yuan Z-S, Jiang B-Y, Wang S-X. Value of interim 18FFDG PET/CT for predicting progression-free survival in stage IIIB/IV EGFRmutant non-small-cell lung cancer patients with EGFR-TKI therapy. Lung Cancer Amst Neth. (2020) 149:137-43. doi: 10.1016/j.lungcan.2020.09.020

4. Barlesi F, Mazieres J, Merlio J-P, Debieuvre D, Mosser J, Lena H, et al. Routine molecular profiling of patients with advanced non-small-cell lung cancer: results of a 1-year nationwide programme of the French Cooperative Thoracic Intergroup (IFCT). Lancet Lond Engl. (2016) 387:141526. doi: 10.1016/S0140-6736(16)00004-0
CMR in NSCLC of ALK / ROS1 rearrangement treated with crizotinib remains a rare event, highlighting ${ }^{18}$ F-FDGPET/CT therapeutic assessment interest of ${ }^{18}$ F-FDG-PET / CT in therapeutic evaluation of the off-target effect of TKI even if this exam is not recommended in routine practice.

Furthermore, these two case reports show the interest of ${ }^{18}$ F-FDG-PET/CT assessment of ALK/ROS1 rearranged NSCLC treated with crizotinib; Patients with a substantial decrease in metabolic activity during TKI treatment will probably benefit from continued treatment. If a metabolic response does not occur within the first weeks of treatment, patients may be spared the unnecessary toxicity of ineffective treatment (21).

In addition, the metabolic response commonly precedes morphological changes. Its potential usefulness for an earlier therapeutic evaluation ( $<3$ months) might be studied in future clinical trials to find new surrogate survival markers.

\section{DATA AVAILABILITY STATEMENT}

The original contributions presented in the study are included in the article/supplementary material, further inquiries can be directed to the corresponding author.

\section{ETHICS STATEMENT}

Written informed consent was obtained from the individual(s) for the publication of any potentially identifiable images or data included in this article.

\section{AUTHOR CONTRIBUTIONS}

KA and LC provided details of the patient and provided initial draft of submission. CL provided details of the patient. DK and RA provided images, image analysis, and helped draft the initial submission. JC helped draft the initial submission. All authors contributed to the article and approved the submitted version.
5. Bergethon K, Shaw AT, Ou S-HI, Katayama R, Lovly CM, McDonald NT, et al. ROS1 rearrangements define a unique molecular class of lung cancers. J Clin Oncol Off J Am Soc Clin Oncol. (2012) 30:86370. doi: 10.1200/JCO.2011.35.6345

6. Shaw AT, Yeap BY, Mino-Kenudson M, Digumarthy SR, Costa DB, Heist RS, et al. Clinical features and outcome of patients with non-small-cell lung cancer who harbor EML4-ALK. J Clin Oncol Off J Am Soc Clin Oncol. (2009) 27:4247-53. doi: 10.1200/JCO.2009.22.6993

7. Kwak EL, Bang Y-J, Camidge DR, Shaw AT, Solomon B, Maki RG, et al. Anaplastic lymphoma kinase inhibition in non-small-cell lung cancer. $N$ Engl J Med. (2010) 363:1693-703. doi: 10.1056/NEJMoa1006448

8. McDermott U, Iafrate AJ, Gray NS, Shioda T, Classon M, Maheswaran S, et al. Genomic alterations of anaplastic lymphoma kinase may sensitize tumors to anaplastic lymphoma kinase inhibitors. Cancer Res. (2008) 68:338995. doi: 10.1158/0008-5472.CAN-07-6186

9. Uguen A, De Braekeleer M. ROS1 fusions in cancer: a review. Future Oncol Lond Engl. (2016) 12:1911-28. doi: 10.2217/fon-2016-0050

10. Lin JJ, Shaw AT. Recent advances in targeting ROS1 in lung cancer. $J$ Thorac Oncol Off Publ Int Assoc Study Lung Cancer. (2017) 12:161125. doi: 10.1016/j.jtho.2017.08.002 
11. Zito Marino F, Rossi G, Cozzolino I, Montella M, Micheli M, Bogina $\mathrm{G}$, et al. Multiplex fluorescence in situ hybridisation to detect anaplastic lymphoma kinase and ROS proto-oncogene 1 receptor tyrosine kinase rearrangements in lung cancer cytological samples. J Clin Pathol. (2020) 73:96-101. doi: 10.1136/jclinpath-2019-206152

12. Camidge DR, Bang Y-J, Kwak EL, Iafrate AJ, Varella-Garcia M, Fox SB, et al. Activity and safety of crizotinib in patients with ALK-positive non-smallcell lung cancer: updated results from a phase 1 study. Lancet Oncol. (2012) 13:1011-9. doi: 10.1016/S1470-2045(12)70344-3

13. Solomon BJ, Mok T, Kim D-W, Wu Y-L, Nakagawa K, Mekhail T, et al. Firstline crizotinib versus chemotherapy in ALK-positive lung cancer. $N$ Engl J Med. (2014) 371:2167-77. doi: 10.1056/NEJMoa1408440

14. Solomon BJ, Kim D-W, Wu Y-L, Nakagawa K, Mekhail T, Felip E, et al. Final overall survival analysis from a study comparing first-line crizotinib versus chemotherapy in ALK-mutation-positive non-small-cell lung cancer. J Clin Oncol Off J Am Soc Clin Oncol. (2018) 36:22518. doi: 10.1200/JCO.2017.77.4794

15. Shaw AT, Ou S-HI, Bang Y-J, Camidge DR, Solomon BJ, Salgia R, et al. Crizotinib in ROS1-rearranged non-small-cell lung cancer. $N$ Engl J Med. (2014) 371:1963-71. doi: 10.1056/NEJMoa14 06766

16. Shaw AT, Riely GJ, Bang Y-J, Kim D-W, Camidge DR, Solomon $\mathrm{BJ}$, et al. Crizotinib in ROS1-rearranged advanced non-small-cell lung cancer (NSCLC): updated results, including overall survival, from PROFILE 1001. Ann Oncol Off J Eur Soc Med Oncol. (2019) 30:1121-6. doi: 10.1093/annonc/mdz131

17. Kerner GSMA, Koole MJB, Bongaerts AHH, Pruim J, Groen HJM. CTMM air force consortium. total body metabolic tumor response in alk positive non-small cell lung cancer patients treated with ALK Inhibition. PloS ONE. (2016) 11:e0149955. doi: 10.1371/journal.pone. 0149955

18. Bos M, Gardizi M, Schildhaus HU, Heukamp LC, Geist T, Kaminsky $\mathrm{B}$, et al. Complete metabolic response in a patient with repeatedly relapsed non-small cell lung cancer harboring ROS1 gene rearrangement after treatment with crizotinib. Lung Cancer Amst Neth. (2013) 81:1423. doi: 10.1016/j.lungcan.2013.02.018

19. Dejust S, Moubtakir A, Prevost A, El Farsaoui K, Morland D. 18F-FDG PET/CT evaluation of crizotinib and lorlatinib therapy in metastatic ROS1-positive non-small cell lung cancer. Clin Nucl Med. (2020) 45:20910. doi: 10.1097/RLU.0000000000002912

20. Christensen JG, Zou HY, Arango ME Li Q, Lee JH, McDonnell SR, Yamazaki S, et al. Cytoreductive antitumor activity of PF-2341066, a novel inhibitor of anaplastic lymphoma kinase and c-Met, in experimental models of anaplastic large-cell lymphoma. Mol Cancer Ther. (2007) 6:331422. doi: 10.1158/1535-7163.MCT-07-0365

21. van Gool MH, Aukema TS, Hartemink KJ, Valdés Olmos RA, van Tinteren H, Klomp HM. FDG-PET/CT response evaluation during EGFRTKI treatment in patients with NSCLC. World J Radiol. (2014) 6:3928. doi: 10.4329/wjr.v6.i7.392

Conflict of Interest: The authors declare that the research was conducted in the absence of any commercial or financial relationships that could be construed as a potential conflict of interest.

Publisher's Note: All claims expressed in this article are solely those of the authors and do not necessarily represent those of their affiliated organizations, or those of the publisher, the editors and the reviewers. Any product that may be evaluated in this article, or claim that may be made by its manufacturer, is not guaranteed or endorsed by the publisher.

Copyright (C) 2021 Amrane, Campedel, Le Meur, Abgral, Kharroubi and Cadranel. This is an open-access article distributed under the terms of the Creative Commons Attribution License (CC BY). The use, distribution or reproduction in other forums is permitted, provided the original author(s) and the copyright owner(s) are credited and that the original publication in this journal is cited, in accordance with accepted academic practice. No use, distribution or reproduction is permitted which does not comply with these terms. 